\title{
The acute effect of a single dose of green tea on the quality and quantity of tears in normal eye subjects
}

This article was published in the following Dove Medical Press journal:

Clinical Ophthalmology

\author{
Ali M Masmali \\ Saud A Alanazi \\ Abdullah G Alotaibi \\ Raied Fagehi \\ Ali Abusharaha \\ Gamal A El-Hiti \\ Cornea Research Chair, Department \\ of Optometry, College of Applied \\ Medical Sciences, King Saud \\ University, Riyadh II433, Saudi Arabia
}

Objective: The study aimed to investigate the acute effect of a single dose of green tea on the quality and quantity of tears in normal eye subjects.

Methods: Forty normal eye subjects (22 men and 18 women) aged 19-39 years were enrolled in the study. Also, an age matching control group (20 males and 20 females) was enrolled for comparison. McMonnies dry eye symptoms questionnaire and slit lamp were used for the exclusion criteria determination. Phenol red thread (PRT) test was performed on both eyes of each subject. A tear sample was collected from the lower tear meniscus of the right eye of each subject for the tear ferning (TF) test, which was performed before (30 minutes) and after (60 minutes) drinking green tea.

Results: The median PRT measurement after green tea consumption was lower (median $[\mathrm{IQR}]=23.50[8.00] \mathrm{mm}$ ) compared to that before consumption (median $[\mathrm{IQR}]=27.00$ [8.75] mm). In contrast, the median TF grade was significantly higher following green tea consumption than that before consumption (median $[\mathrm{IQR}]=2.65[1.23]$ vs $1.50[0.88] \mathrm{mm}$, respectively). The results show that $\mathrm{TF}$ grades increased in $97.5 \%$, and the red phenol thread scores decreased in $80 \%$ of the subjects after green tea consumption compared to those before consumption. The PRT readings and TF grades were significantly different $(P<0.05)$ before and after green tea consumption.

Conclusion: Drinking green tea could have a significant effect on the eye tear film quality. Tear quality appeared to decrease after green tea consumption.

Keywords: dry eye, tear ferning test, green tea, phenol red thread test, tear film, polyphenols

\section{Introduction}

Tea is produced from Camellia sinensis and is one of the most highly consumed drinks worldwide, following water. The chemical structure of green tea is complex. It contains polyphenols ( $30 \%$ dry weight), fibers $(26 \%)$, proteins $(15 \%)$, carbohydrates $(7 \%)$, lipids (7\%), minerals (5\%), amino acids (4\%), pigments $(2 \%)$, and others components. ${ }^{1,2}$ Green tea contains numerous types of polyphenols, such as low molecular weight phenols (eg, catechins), ${ }^{3}$ which account for approximately $25 \%$ of the dry weight of green tea. The most common catechins are epigallocatechin-3-gallate $(60 \%)$, epigallocatechin (19\%), epicatechin-3-gallate (13.5\%), and epicatechin (6.5\%). ${ }^{3,4}$ Catechins have various biological activities, ${ }^{5,6}$ such as hypoglycemic ${ }^{7}$ hypotensive ${ }^{8}$ anticancer, ${ }^{9}$ antioxidant, ${ }^{10,11}$ and antiviral activities. ${ }^{12}$ In addition, green tea has beneficial effects against degenerative diseases,${ }^{13}$ oxidative stress, ${ }^{14}$ and chronic diseases,${ }^{15}$ and decreases the body fat, ${ }^{4}$ lipid profile, ${ }^{16}$ and body weight. ${ }^{17}$ 
The tear film is very important to the health of the eye as well as vision. It consists of three different layers and serves as the first line of defense against foreign bodies. In addition, it lubricates the eye and keeps the surface clean and smooth. ${ }^{18}$ The instability of the tear film function, as well as reduction in tear volume, excessive tear evaporation, or both, can lead to dry eye (DE). There are approximately 30 million patients with DE disease worldwide. ${ }^{18}$ Evaporative and aqueous production deficiency are the most common types of DE disease. The causes of DE are variable, ${ }^{19}$ and it is more common in the elderly ${ }^{20}$ and in women compared to men. ${ }^{21}$ Artificial tears can be used to reduce DE symptoms such as redness, burning sensations, and irritation. A combination of various diagnostic tests along with $\mathrm{DE}$ questionnaires ${ }^{22}$ can be used to detect dryness of the eye and its severity. These tests can measure the quantity or quality of tears. The most widely used techniques include the tear evaporation rate, ${ }^{23}$ tear film breakup time, ${ }^{24}$ meibomian gland dysfunction, ${ }^{25}$ tear osmolarity, ${ }^{26}$ tear ferning (TF), ${ }^{27-30}$ Schirmer test, ${ }^{29}$ phenol red thread (PRT) test, ${ }^{29}$ and tear meniscus height. ${ }^{30}$ The TF test is simple, quick, and can be used efficiently in eye clinics. ${ }^{31}$ Moreover, its validity has been established. ${ }^{32}$

In this study, we report the assessment of the quality and quantity of tears after a single dose of green tea consumption. High polyphenols content in green tea is hypothesized to disturb the tear film stability. To the best of our knowledge, this is the first study to report the effect of green tea on the ocular tear film.

\section{Methods}

Signed informed consent was obtained from each participant before the initiation of the study. The subjects were treated based on the Declaration of Helsinki. ${ }^{33}$ Ethical approval (ethics number CAMS-085-3637) was obtained from the College of Applied Medical Sciences Ethics Committee, King Saud University. Measurements were carried out by the same examiner under normal conditions. A slitlamp was used to examine abnormalities of the eyelids, eyelashes, conjunctiva, cornea, and iris. McMonnies DE symptoms questionnaire was completed by all participants, and the scores were recorded. DE was diagnosed based on a score $>14.5 .^{23,34}$

Forty normal eye subjects (22 males and 18 female subjects) aged 19-39 years (25.98 \pm 6.05 years) were enrolled in the study. An age matching control group, consisting of 40 subjects ( 20 males and 20 females) aged between 20 and 38 years $(23.7 \pm 2.95$ years $)$, was enrolled to test the effect of hot water $(150 \mathrm{~mL})$ on the tear film. The green tea and hot water (approximately $70^{\circ} \mathrm{C}$ ) were consumed within approximately 5 minutes. All subjects were healthy, had no ocular diseases, did not wear contact lenses, and were nonpregnant or breast-feeding. The exclusion criteria include subjects who recently had eye lubricants, ocular surgery, or medications. McMonnies DE symptoms questionnaire and slit lamp were also used for the exclusion criteria determination. The PRT test was performed for both eyes of each subject 30 minutes before a Lipton green tea consumption ( $2.0 \mathrm{G}$ in $150 \mathrm{~mL}$ of hot water). The hot green tea drink was provided in sealed cups to eliminate the effect of the green tea steam. A tear sample was collected from the right eye of each subject for the TF test. The PRT and TF tests were repeated 1 hour after green tea consumption. All tests were performed in the same room, which was equipped with a central air conditioner at room temperature $\left(23^{\circ} \mathrm{C}\right)$ in which humidity was less than $40 \%{ }^{35}$

The PRT test was performed first, followed by the collection of a tear sample for the TF test, and a 10-minute break was allowed between the tests. ${ }^{29}$ The PRT test was performed using a standard procedure ${ }^{29}$ using PRT strips (Zone-Quick, Showa Yakuhin Kako Co, Ltd., Tokyo, Japan). DE was confirmed if the length of the red portion of the PRT third was $<10 \mathrm{~mm}$. A glass capillary tube $(10 \mu \mathrm{L}$, Sigma-Aldrich Chemical Company, Gillingham, UK) was used to collect a tear sample $(1 \mu \mathrm{L})$ from the lower meniscus of the right eye of each subject. Proper extraction of the tear sample was performed in order to prevent tear reflex. The tear sample was dried under normal conditions $\left(23^{\circ} \mathrm{C}\right.$ temperature and $<40 \%$ humidity). ${ }^{35}$ A digital microscope (Olympus DP72, Tokyo, Japan) at a magnification of $10 \times$ was used to observe the TF patterns. The ferns were graded according to the five-point TF grading scale ${ }^{31}$ using 0.1 increments.

The data were collected using the Microsoft Excel program (Microsoft Office 2010, Microsoft Corp., Redmond, WA, USA). The statistical package for the social sciences (SPSS) software (version 22, IBM Crop., Armonk, NY, USA) was used to analyze the data. The data were not normally distributed (Kolmogorov-Smirnov test, $P<0.05$ ) for the McMonnies scores, PRT measurements, and TF grades and the median (IQR) was used to describe the results. Correlation coefficients were described as small (0.10-0.29), medium (0.30-0.49), and strong (0.50-1.00). ${ }^{36}$ The PRT test was performed for both eyes, and there were no significant differences in measurements (using the paired sample $t$-test, $P>0.05)$ between the two eyes. The data of both eyes were highly correlated and, therefore, the measurements from the right eye were used. ${ }^{37}$ 


\section{Results}

Twenty-two male and 18 age-matched female subjects were enrolled in the study. Their ages varied from 19 to 39 years (mean $\pm \mathrm{SD}=25.98 \pm 6.05$ years). An age-matched controlled group (40 subjects; 20 males and 20 females), with a mean of 23.50 \pm 3.70 years, was enrolled to study the effect of hot water. The median (IQR) values for McMonnies questionnaire scores, PRT measurements, and TF grades for both the study and the control groups are shown in Table 1. For the control group, there were no significant differences between the median scores for the same tests before and after the hot water consumption. The median value of the PRT measurements taken before green tea consumption was higher $($ median $[\mathrm{IQR}]=27.00[8.75] \mathrm{mm})$ than that obtained after consumption (median $[\mathrm{IQR}]=23.50$ [8.00] $\mathrm{mm}$ ). In contrast, the median value of the TF grades was significantly higher after green tea consumption (median $[\mathrm{IQR}]=2.65[1.23])$ than it was before the consumption (median $[\mathrm{IQR}]=1.50[0.88] \mathrm{mm}$ ).

The results showed that the PRT measurements were unchanged in $15 \%$ of the subjects $(\mathrm{N}=6)$, increased in $5 \%$ $(\mathrm{N}=2)$, and decreased in $80 \%(\mathrm{~N}=32)$ after the subjects had consumed green tea compared to results before green tea consumption. The TF grades increased in $97.5 \%$ of the subjects $(\mathrm{N}=39)$ after green tea consumption. In addition, the TF grades clearly showed that the TF patterns were unhealthy in $67.5 \%$ of the subjects $(\mathrm{N}=27)$ after green tea consumption. Samples of the TF images obtained from the same subject before and after green tea consumption are shown in Figure 1. There were significant differences (Wilcoxon test, $P<0.05$ ) between the PRT readings and TF grades before and after green tea consumption. The side-by-side box plots of the PRT readings and TF grades before and after green tea consumption are shown in Figures 2 and 3, respectively.

Table I The median (IQR) for McMonnies questionnaire scores, PRT measurements, and TF grades

\begin{tabular}{l|l|l}
\hline \multirow{2}{*}{ Test } & \multicolumn{2}{|l}{ Median (IQR) } \\
\cline { 2 - 3 } & $\begin{array}{l}\text { Study group } \\
(\mathbf{N}=\mathbf{4 0})\end{array}$ & $\begin{array}{l}\text { Control group } \\
\mathbf{( N = 4 0 )}\end{array}$ \\
\hline McMonnies scores & $4.00(4.75)$ & $3.05(\mathrm{I} .65)$ \\
PRTI (mm)* & $27.00(8.75)$ & $29.00(9.15)$ \\
PRT2 (mm)* & $23.50(8.00)$ & $28.00(8.75)$ \\
TFI grades* & $1.50(0.88)$ & $0.78(0.65)$ \\
TF2 grades* & $2.65(I .23)$ & $0.82(0.70)$ \\
\hline
\end{tabular}

Note: $* P<0.05$.

Abbreviations: PRTI, the median for phenol red thread measurements before the consumption of green tea; PRT2, the median for the phenol red thread measurements after the consumption of green tea; TF, tear ferning; TFI, the median for TF grades before the consumption of green tea; TF2, the median for the TF grades after the consumption of green tea.

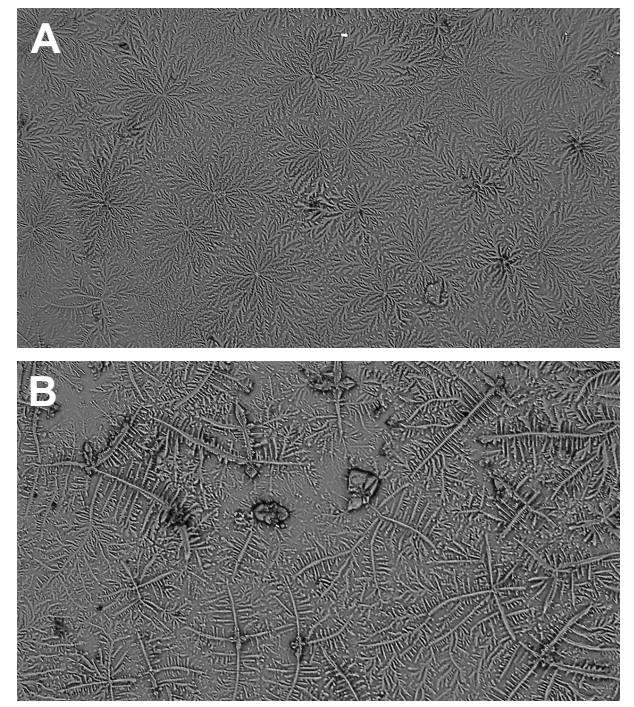

Figure I Images of TF obtained before and after green tea consumption for the same subject.

Notes: (A) before green tea consumption; (B) after green tea consumption. Abbreviation: TF, tear ferning.

The correlation between age, sex, McMonnies questionnaire scores, PRT readings, and TF grades is shown in Table 2. There was a strong correlation $(r=0.836)$ between the PRT measurements, and a medium correlation $(r=0.435)$ between the TF grades before and after green tea was consumed. There was a medium correlation ( $r=0.497)$ between age and McMonnies scores and slight negative correlations ( $r=-0.214$ to -0.167$)$ between age and the PRT measurements.

\section{Discussion}

DE results from the dysfunction of the tear film, and symptoms range from discomfort to corneal damage depending on the severity of the dryness. Factors that cause tear deficiency

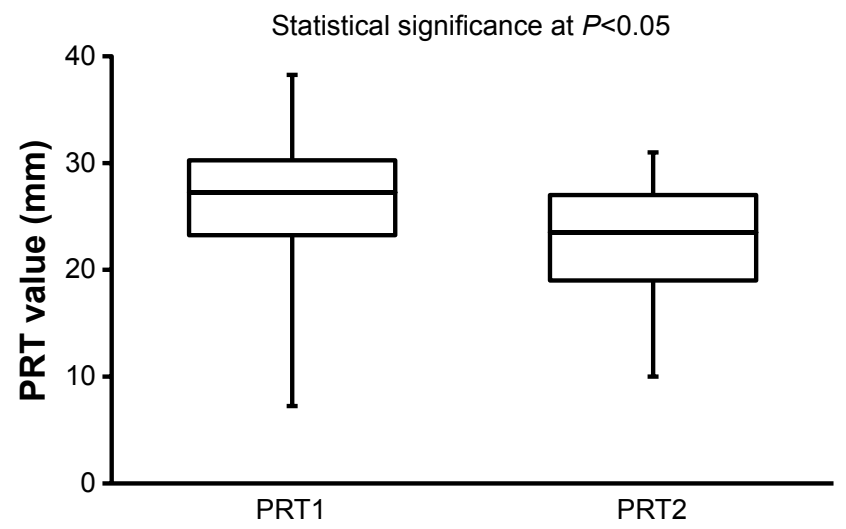

Figure 2 Side-by-side boxplot for PRTI and PRT2 scores.

Abbreviations: PRTI, the median for phenol red thread measurements before the consumption of green tea; PRT2, the median for the phenol red thread measurements after the consumption of green tea. 


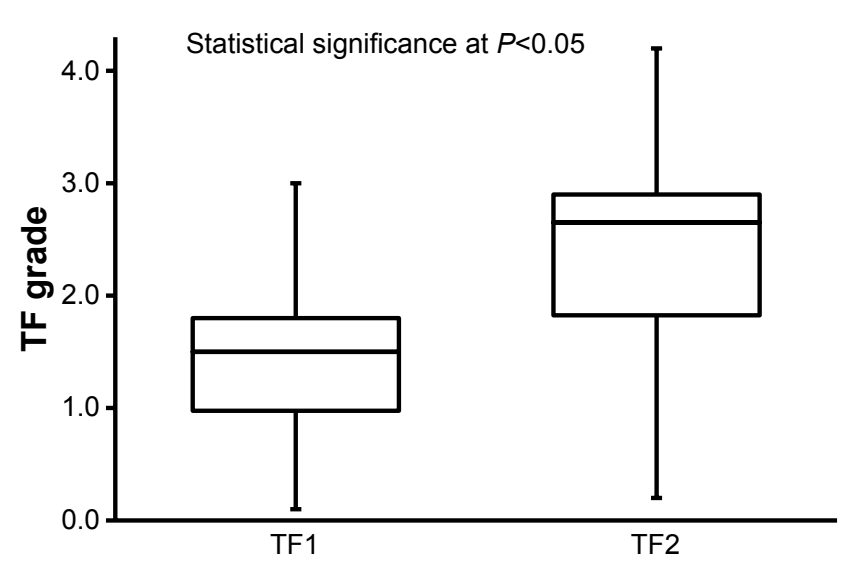

Figure 3 Side-by-side boxplot for TFI and TF2 grades.

Abbreviations: TFI, the median for tear ferning grades before the consumption of green tea; TF2, the median for the tear ferning grades after the consumption of green tea.

could contribute to the dryness of the eye. Discomfort, redness, and inflammation could be controlled in most cases by the use of artificial tears. The current study showed that the median value for the PRT measurements after green tea consumption was lower than that before the tea consumption, but the PRT measurements were normal. The median value of the TF grades was significantly higher after green tea consumption than it was before consumption. The TF grades increased significantly in most of the subjects (97.5\%) after green tea consumption. In addition, unhealthy TF patterns were observed in $67.5 \%$ of the subjects with TF grades $\geq 2$. This result suggests that green tea could have a negative effect on the tear film quality.

Green tea has various health benefits, ${ }^{2}$ including those shown by experiments such as activity against breast cancer ${ }^{38}$ and fungi. ${ }^{39}$ In addition, it acts as an antioxidant in animals ${ }^{40}$ and reduces the body weight in humans. ${ }^{4,41}$ However, high consumption of green tea can be cytotoxic to liver cells ${ }^{42}$ and damage the pancreatic DNA in animals. ${ }^{43}$ Polyphenols, which are the major components of green tea, have been reported to reduce serum lipids in rats ${ }^{44,45}$ and contribute to the formation of oxidized lipids. ${ }^{4}$ Tea leaves can accumulate aluminum at a high percentage. ${ }^{46}$ Polyphenols have an affinity for iron and can significantly reduce its content. ${ }^{47}$ Moreover, polyphenols could interfere with some medications that lead to the reduction in bioavailability of iron and enhance systemic toxicity risk. ${ }^{48}$ Therefore, the harmful effects of green tea on the ocular tear film could be due to the high contents of polyphenols that damage the lipid layer through oxidation. In addition, polyphenols could reduce the concentration of electrolytes (eg, iron) through coordination bonds, and lead to an increased level of aluminum due to accumulation. $^{2}$ Caffeine could also have a similar effect,

Table 2 The correlation between age, sex, McMonnies questionnaire scores, PRT, and TF grades ( $\mathrm{N}=40)$

\begin{tabular}{|c|c|c|c|c|c|c|c|}
\hline Test/correlation & Age & Sex & McMonnies & PRTI & PRT2 & TFI & TF2 \\
\hline \multicolumn{8}{|l|}{$\overline{\text { Age }}$} \\
\hline PC & 1 & $0.466^{\mathrm{a}}$ & $0.497^{\mathrm{a}}$ & -0.214 & -0.167 & 0.199 & 0.074 \\
\hline Sig. & - & 0.002 & 0.001 & 0.184 & 0.303 & 0.219 & 0.649 \\
\hline \multicolumn{8}{|l|}{ Sex } \\
\hline PC & $0.466^{\mathrm{a}}$ & I & 0.136 & -0.159 & -0.140 & 0.020 & 0.297 \\
\hline Sig. & 0.002 & - & 0.403 & 0.326 & 0.390 & 0.904 & 0.063 \\
\hline \multicolumn{8}{|l|}{ McMonnies } \\
\hline PC & $0.497^{a}$ & 0.136 & I & -0.046 & 0.132 & 0.144 & -0.022 \\
\hline Sig. & 0.001 & 0.403 & - & 0.778 & 0.417 & 0.375 & 0.891 \\
\hline \multicolumn{8}{|l|}{ PRTI } \\
\hline PC & -0.214 & -0.159 & -0.046 & I & $0.836^{\mathrm{a}}$ & -0.045 & 0.020 \\
\hline Sig. & 0.184 & 0.326 & 0.778 & - & 0.000 & 0.782 & 0.902 \\
\hline \multicolumn{8}{|l|}{ PRT2 } \\
\hline $\mathrm{PC}$ & -0.167 & -0.140 & 0.132 & $0.836^{a}$ & I & -0.069 & 0.016 \\
\hline Sig. & 0.303 & 0.390 & 0.417 & 0.000 & - & 0.671 & 0.922 \\
\hline \multicolumn{8}{|l|}{ TFI } \\
\hline PC & 0.199 & 0.020 & 0.144 & -0.045 & -0.069 & I & $0.435^{\mathrm{a}}$ \\
\hline Sig. & 0.219 & 0.904 & 0.375 & 0.782 & $0.67 \mid$ & - & 0.005 \\
\hline \multicolumn{8}{|l|}{ TF2 } \\
\hline PC & 0.074 & 0.297 & -0.022 & 0.020 & 0.016 & $0.435^{\mathrm{a}}$ & I \\
\hline Sig. & 0.649 & 0.063 & 0.891 & 0.902 & 0.922 & 0.005 & - \\
\hline
\end{tabular}

Note: ${ }^{\text {aC }}$ orrelation is significant at 0.01 level (2-tailed).

Abbreviations: PC, Pearson correlation coefficient; PRTI, the median for phenol red thread measurements before the consumption of green tea; PRT2, the median for the phenol red thread measurements after the consumption of green tea; Sig., significance (2-tailed); TF, tear ferning; TFI, the median for TF grades before the consumption of green tea; TF2, the median for the TF grades after the consumption of green tea. 
but not as significant as for polyphenols. The disruption in the proportions of lipids or electrolytes (eg, aluminum and iron) or both could contribute to the negative effects of green tea on the tear film.

The results of the current study suggest that green tea could negatively affect the tear film tear quality. However, detailed studies are still needed to establish a direct link between the quality and quantity of tears and green tea. Such studies should consider the limitations associated with the current study, such as a small sample size and the use of other tests to evaluate the tear film.

\section{Conclusion}

Green tea has a significant effect on the tear film quality of the eye. Tear quality appeared to decrease after green tea consumption, possibly due to the disruption in lipids or electrolyte content or both. However, various studies have shown the beneficial effects of green tea, such as a reduction of blood sugar and pressure.

\section{Acknowledgments}

The authors are grateful to the Deanship of Scientific Research, King Saud University for funding through the Vice Deanship of Scientific Research Chairs.

\section{Disclosure}

The authors report no conflicts of interest in this work.

\section{References}

1. Smith TJ. Green tea polyphenols in drug discovery - a success or failure? Expert Opin Drug Discov. 2011;6(6):589-595. doi:10.1517/17460441 .2011 .570750

2. Chacko SM, Thambi PT, Kuttan R, Nishigaki I. Beneficial effects of green tea: a literature review. Chin Med. 2010;5:8546513. doi:10.1186/ 1749-8546-5-13

3. Nawab A, Farooq N. Review on green tea constituents and its negative effects. J Pharm Innov. 2015;4(1):21-24.

4. Nagao T, Komine Y, Soga S, et al. Ingestion of a tea rich in catechins leads to a reduction in body fat and malondialdehyde-modified LDL in men. Am J Clin Nutr. 2005;81(1):122-129. doi:10.1093/ajcn/81.1.122

5. Lima GPP, Vianello F, Corrêa CR, Da Silva Campos R-A, Borguini MG. Polyphenols in fruits and vegetables and its effect on human health. Food Nutr Sci. 2014;5(11):1065-1082.

6. Cabrera G, Artacho R, Giménez R. Beneficial effects of green tea - a review. J Am Coll Nutr. 2006;25(2):79-99. doi:10.1080/07315724.20 06.10719518

7. Henry JP, Stephens-Larson P. Reduction of chronic psychosocial hypertension in mice by decaffeinated tea. Hypertension. 1984;6(3):437-444.

8. Maruyama K, Iso H, Sasaki S, Fukino Y. The association between concentrations of green tea and blood glucose levels. $J$ Clin Biochem Nutr. 2009;44(1):41-45. doi:10.3164/jcbn.08-13

9. Miyata Y, Matsuo T, Araki K, et al. Anticancer effects of green tea and the underlying molecular mechanisms in bladder cancer. Medicines (Basel). 2018;5(3):87. doi:10.3390/medicines5030087

10. Forester AC, Lambert JD. Antioxidant effects of green tea. Mol Nutr Food Res. 2011;55(6):844-854. doi:10.1002/mnfr.201000566
11. Cavet ME, Harrington KL, Vollmer TR, Ward KW, Zhang J-Z. Antiinflammatory and anti-oxidative effects of the green tea polyphenol epigallocatechin gallate in human corneal epithelial cells. Mol Vis. 2011; 17:33-542.

12. Song JM, Lee KH, Seong BL. Antiviral effect of catechins in green tea on influenza virus. Antiviral Res. 2005;68(2):66-74. doi:10.1016/j. antiviral.2005.06.010

13. Vanessa C, Gary W. A review of the health effects of green tea catechins in in vivo animal models. $J$ Nutr. 2004;134(12):3431S-3440S. doi: $10.1093 / \mathrm{jn} / 134.12 .3431 \mathrm{~S}$

14. Babu PV, Sabitha KE, Shyamaladevi CS. Therapeutic effect of green tea extract on oxidative stress in aorta and heart of streptozotocin diabetic rats. Chem Biol Interact. 2006;162(2):114-120. doi:10.1016/j. cbi.2006.04.009

15. Zaveri NT. Green tea and its polyphenolic catechins: medicinal uses in cancer and noncancer applications. Life Sci. 2006;78(18):2073-2080. doi:10.1016/j.1fs.2005.12.006

16. Gad SB, Zaghloul DM. Beneficial effects of green tea extract on liver and kidney functions, ultrastructure, lipid profile and hematological parameters in aged male rats. Glob Veterinaria. 2013;11(2):191-205.

17. Hursel R, Viechtbauer W, Westerterp-Plantenga MS. The effects of green tea on weight loss and weight maintenance: a meta-analysis. Int J Obes. 2009;33(9):956-961. doi:10.1038/ijo.2009.135

18. Phadatare SP, Momin M, Nighojkar P, Askarkar S, Singh KK. A comprehensive review on dry eye disease: diagnosis, medical management, recent developments, and future challenges. Adv Pharm. 2015; 2015:704946.

19. Lemp MA, Foulks GN. Definition and classification of dry eye. Report of the diagnosis and classification subcommittee of the dry eye workshop (DEWS). Ocul Surf. 2007;5(2):75-92. doi:10.1016/ S1542-0124(12)70081-2

20. Sharma A, Hindman HB. Aging: a predisposition to dry eyes. J Ophthalmol. 2014;2014:781683.

21. Hashemi H, Khabazkhoob M, Kheirkhah A, et al. Prevalence of dry eye syndrome in an adult population. Clin Exp Ophthalmol. 2014; 42(3):242-248. doi:10.1111/ceo.12183

22. Amparo F, Schaumberg DA, Dana R. Comparison of two questionnaires for dry eye symptom assessment: the ocular surface disease index and the symptom assessment in dry eye. Ophthalmology. 2015; 122(7):1498-1503. doi:10.1016/j.ophtha.2015.02.037

23. Abusharaha A, Alturki AA, Alanazi SA, et al. An assessment of the tear evaporation rate in thyroid gland patients. Clin Ophthalmol. 2019;13: 131-135. doi:10.2147/OPTH.S188614

24. Cho P, Ho KY, Huang YC, Chui HY, Kwan C. Comparison of noninvasive tear break-up time measurements from black and white background instruments. Optom Vis Sci. 2004;81(6):436-441.

25. Qiao J, Yan X. Emerging treatment options for meibomian gland dysfunction. Clin Ophthalmol. 2013;7:1797-1803.

26. Masmali A, Alrabiah S, Alharbi A, El-Hiti GA, Almubrad T. Investigation of tear osmolarity using the TearLab ${ }^{\mathrm{TM}}$ osmolarity system in normal adults in Saudi Arabia. Eye Cont Lens. 2014;40(2):74-78. doi:10.1097/ ICL.0000000000000002

27. Masmali AM, Purslow C, Murphy PJ. The Tear ferning test: a simple clinical technique to evaluate the ocular tear film. Clin Exp Optomol. 2014;97(5):399-406. doi:10.1111/cxo.2014.97.issue-5

28. Masmali AM, Al-Qhtani S, Al-Gasham TM, El-Hiti GA, Purslow C, Murphy PJ. Application of a new grading scale for tear ferning in nondry eye and dry eye subjects. Cont Lens Anterior Eye. 2015;38(1):39-43. doi:10.1016/j.clae.2014.09.007

29. Masmali A, Alqahtani TA, Alharbi A, El-Hiti GA. Comparative study of repeatability of phenol red thread test versus Schirmer's test in normal adults in Saudi Arabia. Eye Cont Lens. 2014;40(3):127-131. doi:10.1097/ICL.0000000000000025

30. Ibrahim OM, Dogru M, Takano Y, et al. Application of visante optical coherence tomography tear meniscus height measurement in the diagnosis of dry eye disease. Ophthalmology. 2010;117(10):1923-1929. doi:10.1016/j.ophtha.2010.01.057 
31. Masmali AM, Murphy PJ, Purslow C. Development of a new grading scale for tear ferning. Cont Lens Anterior Eye. 2014;37(3):178-184. doi:10.1016/j.clae.2013.09.011

32. Masmali AM, Al-Bahlal JM, El-Hiti GA, et al. Repeatability and diurnal variation of tear ferning test. Eye Cont Lens. 2015;41(5):262-267. doi:10.1097/ICL.0000000000000116

33. World Medical Association Declaration of Helsinki. Ethical principles for medical research involving human subjects. JAMA. 2013; 310(20):2191-2194. doi:10.1001/jama.2013.281053

34. Nichols KK, Nichols JJ, Mitchell GL. The reliability and validity of McMonnies dry eye index. Cornea. 2004;23(4):365-371. doi:10.1097/ 00003226-200405000-00010

35. Masmali MA, Maeni YA, El-Hiti GA, Murphy PJ, Almubrad T. Investigation of ocular tear ferning in controlled and uncontrolled diabetic subjects. Eye Cont Lens. 2018;44(S2):S70-S75. doi:10.1097/ ICL.0000000000000419

36. Cohen J. Statistical Power Analysis for the Behavioral Sciences. 2nd ed. Hillsdale (NJ): Lawrence Erlbaum Associates; 1988.

37. McAlinden C, Khadka J, Pesudovs K. Statistical methods for conducting agreement (comparison of clinical tests) and precision (repeatability or reproducibility) studies in optometry and ophthalmology. Ophthalmic Physiol Opt. 2010;31(4):330-338. doi:10.1111/j.14751313.2011.00851.x

38. Zhang M, Holman CD, Huang J-P Xie X. Green tea and the prevention of breast cancer: a case-control study in Southeast China. Carcinogenesis. 2005;28(5):1074-1078. doi:10.1093/carcin/bg1252

39. Hirasawa M, Takada K. Multiple effects of green tea catechin on the antifungal activity of antimycotics against Candida albicans. J Antimicrob Chemother. 2004;53(2):225-229. doi:10.1093/jac/dkh046

40. Skrzydlewska E, Ostrowska J, Farbiszewski R, Michalak K. Protective effect of green tea against lipid peroxidation in the rat liver, blood serum and the brain. Phytomedicine. 2002;9(3):232-238. doi:10.1078/ 0944-7113-00119
41. Boschmann M, Thielecke F. The effects of epigallocatechin-3-gallate on thermogenesis and fat oxidation in obese men: a pilot study. $J \mathrm{Am}$ Coll Nutr. 2007;26(4):389S-395S.

42. Schmidt M, Schmitz HJ, Baumgart A, et al. Toxicity of green tea extracts and their constituents in rat hepatocytes in primary culture. Food Chem Toxicol. 2005;43(2):307-314. doi:10.1016/j.fct.2004.12.006

43. Takabayashi F, Tahara S, Kanerko T, Harada N. Effect of green tea catechins on oxidative DNA damage of hamster pancreas and liver induced by N-nitrosobis(2-oxopropyl)amine and/or oxidized soybean oil. Biofactors. 2004;21(1-4):335-337. doi:10.1002/biof.552210165

44. Muramatsu K, Fukuyo M, Hara Y. Effect of green tea catechins on plasma cholesterol level in cholesterol-fed rats. J Nutr Sci Vitaminol. 1986;32(6):613-622. doi:10.3177/jnsv.32.613

45. Mesbahzadeh B, Akbari M, Kor NM, Zadeh JB. The effects of different levels of peppermint alcoholic extract on body-weight gain and blood biochemical parameters of adult male Wistar rats. Electron Physician. 2015;7(6):1376-1380.

46. Cost LM, Gouveia ST, Nobrega JA. Comparison of heating extraction procedures for $\mathrm{Al}, \mathrm{Ca}, \mathrm{Mg}$ and $\mathrm{Mn}$ in tea samples. Anal Sci. 2002; 18(3):313-318. doi:10.2116/analsci.18.313

47. Hamdaoui MH, Chabchob S, Héidhili A. Iron bioavailability and weight gains to iron-deficient rats fed a commonly consumed Tunisian meal "bean seeds ragout" with or without beef and with green or black tea decoction. J Trace Elem Med Biol. 2003;17(3):159-164. doi:10.1016/ S0946-672X(03)80020-2

48. Schönthal AH. Adverse effects of concentrated green tea extracts. $M o l$ Nutr Food Res. 2011;55(6):874-885. doi:10.1002/mnfr.201000566
Clinical Ophthalmology

\section{Publish your work in this journal}

Clinical Ophthalmology is an international, peer-reviewed journal covering all subspecialties within ophthalmology. Key topics include: Optometry; Visual science; Pharmacology and drug therapy in eye diseases; Basic Sciences; Primary and Secondary eye care; Patient Safety and Quality of Care Improvements. This journal is indexed on Submit your manuscript here: http://www.dovepress.com/clinical-ophthalmology-journal

\section{Dovepress}

PubMed Central and CAS, and is the official journal of The Society of Clinical Ophthalmology (SCO). The manuscript management system is completely online and includes a very quick and fair peer-review system, which is all easy to use. Visit http://www.dovepress.com/ testimonials.php to read real quotes from published authors. 